\title{
FK506 prevents mitochondrial-dependent apoptotic cell death induced by 3-nitropropionic acid in rat primary cortical cultures
}

\author{
Sandra Almeida, António Domingues, Luís Rodrigues, \\ Catarina R. Oliveira, and A. Cristina Rego* \\ Center for Neuroscience and Cell Biology of Coimbra and Institute of Biochemistry, Faculty of Medicine, University of Coimbra, 3004-504 Coimbra, Portugal
}

Received 18 February 2004; revised 17 June 2004; accepted 9 July 2004

Available online 30 September 2004

\begin{abstract}
The mitochondrial toxin 3-nitropropionic acid (3-NP) has been largely used to study neurodegenerative disorders in which bioenergetic defects are implicated. In the present study, we analyzed the molecular pathways involved in FK506 neuroprotection against cell death induced by 3-NP, using cultured cortical neurons. 3-NP induced cytochrome $c$ release and increased caspases $-2,-3,-8$, and -9-like activities, although, calpain activity was not significantly affected. FK506 decreased cytochrome $c$ release and caspase-3-like activity induced by 3-NP, without changing the activities of other caspases. FK506 also decreased the number of apoptotic neurons, determined by Hoechst. Under these conditions, FK506 alone significantly reduced calcineurin activity by about $50 \%$. Our results also showed a decrease in mitochondrial Bax and an increase in mitochondrial Bcl-2 levels upon exposure to FK506 and 3-NP. However, no significant changes occurred in total Bcl-2 and Bax levels. Altogether, the results suggest that FK506 neuroprotection against 3-NP-induced apoptosis is associated with the redistribution of $\mathrm{Bcl}-2$ and $\mathrm{Bax}$ in the mitochondrial membrane.
\end{abstract}

(C) 2004 Elsevier Inc. All rights reserved.

Keywords: FK506; 3-Nitropropionic acid; Mitochondria; Bcl-2; Bax; Apoptosis; Cortical neurons

\section{Introduction}

Neurodegenerative diseases are thought to be associated with the impairment of neuronal energy metabolism. Several studies have reported the occurrence of mitochondrial dysfunction in brains from Huntington disease (HD) patients, namely, through the inhibition of respiratory chain complexes II and III (Browne et al., 1997; Gu et al., 1996). Systemic administration of the mitochondrial toxin 3-nitropropionic acid (3-NP), an irreversible inhibitor of

\footnotetext{
* Corresponding author. Fax: +351 239822776.

E-mail address: acrego@cnc.cj.uc.pt (A.C. Rego).

Available online on ScienceDirect (www.sciencedirect.com.)
}

succinate dehydrogenase, was shown to elicit behavioral abnormalities and cortical and striatal neuronal degeneration in rats and nonhuman primates, similar to that seen in humans with HD (Beal et al., 1993; Brouillet et al., 1998).

3-NP produces neuronal death secondary to perturbed intracellular calcium homeostasis. In primary rat neuronal cultures, 3NP induces a gradual increase in mitochondrial calcium and reactive oxygen species which are prevented in the presence of caspase inhibitors (Lee et al., 2002a). At higher concentrations, 3$\mathrm{NP}$ administration results in a massive elevation of mitochondrial and cytosolic calcium, a decrease in ATP levels, a rapid mitochondrial membrane depolarization, and the activation of calpains (Lee et al., 2002b; Nasr et al., 2003; Pang and Geddes, 1997). Under these conditions, caspase activity is not affected, which is in agreement with cells undergoing death by necrosis (Nasr et al., 2003). On the other hand, apoptotic cell death induced by 3 -NP has been largely documented through the analysis of DNA fragmentation by TUNEL staining, the release of cytochrome $c$, the activation of caspase-3, and alterations in the levels of the apoptosis-related protein markers Bax and Bcl-2 (Kim and Chan, 2001; Rodrigues et al., 2000; Vis et al., 2002).

FK506 has been described to act as a selective inhibitor of calcineurin (or protein phosphatase 2B) (Griffith et al., 1995; Liu et al., 1991), a ubiquitously expressed $\mathrm{Ca}^{2+} / \mathrm{CaM}$-dependent protein phosphatase that is a critical component of several $\mathrm{Ca}^{2+}$ dependent signaling pathways. Calcineurin regulates a number of transcription factors and ion channels and is involved in long-term depression of postsynaptic potential and synaptic vesicle recycling (Crabtree, 2001; Kramer et al., 2003). Calcineurin has been also implicated in neuronal cell death induced by insults that elevate cytosolic calcium (Ankarcrona et al., 1996; Agostinho and Oliveira, 2003; Wang et al., 1999; Wood and Bristow, 1998). Calcineurin can promote apoptosis through dephosphorylation of $\mathrm{Bad}$ at ${ }^{112}$ Ser and ${ }^{136}$ Ser (Wang et al., 1999), a proapoptotic member of the Bcl-2 family. Dephosphorylated Bad translocates from the cytosol to the mitochondria where it inhibits antiapoptotic activity of Bcl-2 and $\mathrm{Bcl}-\mathrm{x}_{\mathrm{L}}$, ultimately, leading to cell death (Desagher and Martinou, 2000, for review). In accordance, FK506 
was found to decrease apoptosis of cerebellar granule and cortical cultures after exposure to glutamate (Ankarcrona et al., 1996; Asai et al., 1999) or to amyloidogenic peptides (Agostinho and Oliveira, 2003). FK506 also prevented calcineurin-mediated dephosphorylation of nitric oxide synthase, leading to neuroprotection (Dawson et al., 1993; Nishino et al., 1996). In addition, FK506 was shown to increase the survival of grafted embryonic dopamine neurons (Castilho et al., 2000). However, the precise mechanisms of neuroprotection evoked by FK506 are not fully understood.

Thus, in the present study, we evaluated the protective effect of FK506 in the apoptotic process induced by the mitochondrial toxin 3-NP. Our results indicate that FK506 prevents 3-NP-induced cytochrome $c$ release, caspase- 3 activation, and DNA fragmentation by decreasing mitochondrial Bax and increasing mitochondrial Bcl-2 levels.

\section{Materials and methods}

\section{Materials}

Neurobasal medium and B-27 supplement were purchased from GIBCO (Paisley, UK). The protease inhibitor cocktail (chymostatin, pepstatin A, leupeptin, and antipain), penicillin/streptomycin, $N$-acetyl-Ile-Glu-Pro-Asp- $p$-nitroanilide (Ac-IEPD- $p$ NA), nigericin, 3-(4,5-dimethylthiazol-2-yl)-2,5-diphenyltetrazolium bromide (MTT), and 3-nitropropionic acid were from Sigma Chemical Co. (St. Louis, MO, USA). FK506, Streptomyces sp. (Tacrolimus), $N$ acetyl-Asp-Glu-Val-Asp- $p$-nitroanilide (Ac-DEVD- $p$ NA), and Calcineurin Cellular Activity Assay Kit were obtained from Calbiochem (Darmstadt, Germany). N-acetyl-Val-Asp-Val-AlaAsp- $p$-nitroanilide (Ac-VDVAD- $p$ NA) and $N$-acetyl-Leu-GluHis-Asp- $p$-nitroanilide (Ac-LEHD- $p$ NA) were from BioSource International, Inc. (Nivelles, Belgium). $N$-succinyl-Leu-Leu-ValTyr-AMC (Suc-LLVY-AMC) was from Bachem (Bubendorf, Switzerland). Primary antibodies anti-cytochrome $c$, anti-Bad, anti- $\alpha$-tubulin, and anti-Bcl-2 and anti-Bax were from PharMingen (San Diego, CA, USA), Transduction Laboratories (Lexington, UK), Zymed Laboratories Inc. (San Francisco, CA, USA), and Santa Cruz Biotechnology Inc. (Santa Cruz, CA, USA), respectively. The antibody against $\alpha$-spectrin, mAb 1622, was obtained from Chemicon (Temecula, CA). Acetoxymethyl ester of BCECF, $2^{\prime}, 7^{\prime}$-bis-(carboxyethyl)-5(and-6)carboxyfluorescein (BCECFAM) and Hoechst 33342 were from Molecular Probes (Eugene, OR, USA). All other reagents were of analytical grade.

\section{Cell culture}

Cortical neurons were isolated from 15- to 16-day-old Wistar rat embryos, and the cortical tissues were loaded in Krebs medium (in mM: $120.9 \mathrm{NaCl}, 4.8 \mathrm{KCl}, 1.2 \mathrm{KH}_{2} \mathrm{PO}_{4}, 25.5 \mathrm{NaHCO}_{3}, 13$ glucose, 10 HEPES, $\mathrm{pH} 7.4$ ) containing $0.3 \% \mathrm{BSA}, 0.05 \%$ trypsin, and $0.04 \mathrm{mg} / \mathrm{ml} \mathrm{DNase}$ for $10 \mathrm{~min}$ at $37^{\circ} \mathrm{C}$. The reaction was stopped by addition of the same volume of Krebs medium containing $0.3 \%$ BSA, $0.075 \%$ trypsin inhibitor and $0.04 \mathrm{mg} / \mathrm{ml}$ DNase. This solution was removed after centrifugation $(180 \times g$, for $5 \mathrm{~min}$ ), and the cells were dissociated in a new Krebs medium. After removal of the latter solution, the neurons were resuspended in neurobasal medium supplemented with $2 \%$ B-27, $0.2 \mathrm{mM}$ glutamine, $100 \mathrm{U} / \mathrm{ml}$ penicillin, and $0.1 \mathrm{mg} / \mathrm{ml}$ streptomycin and cultured in a humidified incubator at $37^{\circ} \mathrm{C}\left(95 \%\right.$ air and $\left.5 \% \mathrm{CO}_{2}\right)$. Cortical cultures contained few glial cells (less than 10\%) as assessed by immunofluorescence using anti-MAP2 (microtubuleassociated protein) and anti-GFAP (glial fibrillary acidic protein) (not shown).

Neurons isolated from the cortex were cultured for 3-6 days and then incubated with $0.1-10 \mathrm{mM}$ 3-NP for $24 \mathrm{~h}$. Before incubation with $3-\mathrm{NP}$, some cells were pretreated with $1 \mu \mathrm{M}$ FK506 for 20-30 min. Stock 3-NP solution was dissolved in water and brought to $\mathrm{pH} 7.4$ with $\mathrm{NaOH}$. Stock solutions of FK506 were prepared in DMSO.

Analysis of cell viability

\section{MTT assay}

The reduction status of the cells were measured by a colorimetric assay for cell survival, using 3-(4,5-dimethylthiazol2-yl)-2,5-diphenyltetrazolium bromide (MTT), according to the method described by Mosmann (1983). MTT $(0.5 \mathrm{mg} / \mathrm{ml})$ in $\mathrm{Na}^{+}$ medium (in mM: $132 \mathrm{NaCl}, 1.2 \mathrm{NaH}_{2} \mathrm{PO}_{4}, 1.4 \mathrm{MgCl}_{2}, 4 \mathrm{KCl}, 10$ HEPES, 6 glucose, and $1 \mathrm{CaCl}_{2}, \mathrm{pH}$ 7.4) was added to the cultures and incubated for $2 \mathrm{~h}$ at $37^{\circ} \mathrm{C}$ in the dark. When taken up by living cells, MTT is converted to a water-insoluble blue product (formazan). The precipitated dye was dissolved in $0.04 \mathrm{M} \mathrm{HCl}$ in isopropanol and colorimetrically quantitated (absorbance at $570 \mathrm{~nm}$ ). Values were expressed as the percentage of optical density of control cells, in the absence of 3-NP or FK506.

\section{Lactate dehydrogenase (LDH) measurements}

The integrity of the plasma membrane was determined by monitoring the activity of the cytoplasmic enzyme LDH in the extracellular incubation medium, which represents a common procedure to determine membrane leakage and cellular damage. Assessment of intracellular LDH was determined after lysing the cells with $10 \mathrm{mM}$ HEPES (pH 7.4) plus $0.01 \%$ Triton X-100 and freezing at $-80^{\circ} \mathrm{C}$. Cell debris in both aliquots (intracellular and extracellular) were removed by centrifugation at $14,000 \mathrm{rpm}$ (Eppendorf Centrifuge 5417R), for $10 \mathrm{~min}$. LDH activity was determined spectrophotometrically (Perkin-Elmer Lambda-2), by following the rate of conversion of reduced nicotinamide adenine dinucleotide (NADH) to oxidized nicotinamide adenine dinucleotide $\left(\mathrm{NAD}^{+}\right)$at $340 \mathrm{~nm}$, according to the method of Bergmeyer and Bernt (1974). LDH released into the extracellular medium was expressed as a percentage of the total LDH activity in the cells [\% of $\mathrm{LDH}$ released $=$ extracellular $\mathrm{LDH} /($ extracellular $\mathrm{LDH}+$ intracellular LDH)].

\section{Intracellular pH measurements}

Measurement of intracellular $\mathrm{pH}(\mathrm{pHi})$ was assessed by following the changes in fluorescence of the $\mathrm{pH}$-sensitive probe $2^{\prime}, 7^{\prime}$-bis-(carboxyethyl)-5(and-6)carboxyfluorescein (BCECF) similarly as described by Rego and Oliveira (1998). Cortical cells were loaded with $5 \mu \mathrm{M}$ BCECF-AM for $45 \mathrm{~min}$, at $37^{\circ} \mathrm{C}$, in culture medium, in an atmosphere of $95 \%$ air and $5 \% \mathrm{CO}_{2}$, to avoid major changes in cellular $\mathrm{pH}$. Loaded cells were further incubated for $20 \mathrm{~min}$ in cultured medium without the probe to allow hydrolysis of the acetoxymethyl ester. The cells were rinsed, and fluorescence signals were monitored for $10 \mathrm{~min}$ in $\mathrm{Na}^{+}$medium, with double excitation at 440 and $490 \mathrm{~nm}$ and emission at $530 \mathrm{~nm}$, by using a temperature-controlled SPEX Fluorolog spectrometer. The fluo- 
rescence intensity ratio was calibrated by incubating the cells in $\mathrm{K}^{+}$ medium (identical with the $\mathrm{Na}^{+}$medium, except that $\mathrm{NaCl}$ was replaced with $132 \mathrm{mM} \mathrm{KCl}$ ) containing $10 \mu \mathrm{M}$ nigericin, a $\mathrm{K}^{+} / \mathrm{H}^{+}$ ionophore. A calibration curve of fluorescence versus $\mathrm{pH}$ was constructed by changing the $\mathrm{pH}(6.0$ to 8.0$)$ of the $\mathrm{K}^{+}$medium on different coverslips.

\section{Calcineurin activity assay}

Calcineurin activity was assessed using Calcineurin Cellular Activity Assay Kit, according to the manufacturer's instruction. Briefly, the phosphopeptide derived from the RII subunit of cAMPdependent kinase (RII phosphopeptide - DLDVPIPGRFDRRVpSVAAE), a well-known substrate for calcineurin, was used as the substrate. Cortical neurons were lysed in lysis buffer $(50 \mathrm{mM}$ Tris$\mathrm{HCl}(\mathrm{pH}$ 7.5), $1 \mathrm{mM}$ DTT, $100 \mu \mathrm{M}$ EDTA, $100 \mu \mathrm{M}$ EGTA, $0.2 \%$ NP-40). After removal of free phosphate, the lysate was incubated with RII phosphopeptide $(1.64 \mathrm{mg} / \mathrm{ml})$ in assay buffer containing $100 \mathrm{mM} \mathrm{NaCl}, 50 \mathrm{mM}$ Tris- $\mathrm{HCl}$ (pH 7.5), $6 \mathrm{mM} \mathrm{MgCl} 2,0.5 \mathrm{mM}$ DTT, $0.025 \% \mathrm{NP}-40$ with $0.5 \mathrm{mM} \mathrm{CaCl} 2$ or with $10 \mathrm{mM}$ EGTA. After $30 \mathrm{~min}$ at $30^{\circ} \mathrm{C}$, reactions were terminated by adding $100 \mu \mathrm{l}$ GREEN $^{\mathrm{TM}}$ reagent, and absorbance was measured at $620 \mathrm{~nm}$ using a 96-well plate reader (SLT.SPECTRA).

\section{Caspase protease activity assay}

Caspases-like activities were determined according to modifications of the method described by Cregan et al. (1999). After the incubation period, the culture media were removed, and cells were washed in PBS. The lysis buffer (in mM: 25 HEPES, $2 \mathrm{MgCl}_{2} \cdot 6 \mathrm{H}_{2} \mathrm{O}, 1$ EDTA, 1 EGTA, pH 7.4) supplemented with $1 \mathrm{mM}$ 1,4-dithiotreitol (DTT), $1 \mathrm{mM}$ phenylmethylsulfonyl fluoride (PMSF), and 1:1000 protease inhibitor cocktail (chymostatin, pepstatin A, leupeptin, and antipain, $1 \mathrm{mg} / \mathrm{ml}$ ) was added to cells, on ice. Cortical cell lysates were frozen three times in liquid $\mathrm{N}_{2}$ and centrifuged $(14,000 \mathrm{rpm}$, for $10 \mathrm{~min}$, Eppendorf Centrifuge $5417 \mathrm{R}$ ). The resulting supernatants were assayed for protein content by the Sedmak method (Sedmak and Grossero, 1977). To measure caspase activity, 25-65 $\mu \mathrm{g}$ of protein was added to a reaction buffer [25 mM HEPES, $10 \%(\mathrm{~m} / \mathrm{v})$ sucrose, $0.1 \%(\mathrm{~m} / \mathrm{v}) \quad 3-[(3$-cholamidopropyl) dimethylammonio]-1-propane-sulfonate (CHAPS), $\mathrm{pH}$ 7.5] containing the colorimetric substrates $(100 \mu \mathrm{M})$ for caspase-2 (Ac-VDVAD- $p$ NA), caspase-3 (Ac-DEVD- $p$ NA), caspase-8 (Ac-IETD- $p$ NA), or caspase-9 (AcLEHD- $p$ NA)-like activities. The reaction mixtures were incubated at $37^{\circ} \mathrm{C}$ for $2 \mathrm{~h}$, and the formation of $p \mathrm{NA}$ was measured at 405 $\mathrm{nm}$ using a 96-well plate reader (SLT.SPECTRA). Caspases-like activities were calculated as the increase above the control for equal protein loaded.

\section{Calpain activity assay}

Calpain activity was assessed by measuring the hydrolysis of 7-amino-4-methyl-coumarin (AMC) dye from the $\mathrm{C}$ terminus of the peptide substrate $N$-succinyl-Leu-Leu-Val-Tyr-AMC (SucLLVY-AMC). Cortical cells were loaded in $\mathrm{Na}^{+}$medium containing $80 \mu \mathrm{M}$ Suc-LLVY-AMC, and fluorescence signals were monitored for $1 \mathrm{~h}$, with excitation at $380 \mathrm{~nm}$ and emission at $460 \mathrm{~nm}$, by using a temperature-controlled SPEX Fluorolog spectrometer. As a negative control, fluorescence was measured under the same conditions using $\mathrm{Na}^{+}$medium without calcium and containing $10 \mathrm{mM}$ EGTA. To calculate the relative calpain activity, the rate of increase in fluorescence was normalized to control activity, which was set at 1 .

\section{Nuclear morphology assay}

The nuclear morphology of cortical neurons was analyzed by fluorescence microscopy of living cells using Hoechst 33342 dye. After incubation for $24 \mathrm{~h}$, the medium was replaced by new neurobasal medium, and the cortical neurons remained in culture for an additional $24 \mathrm{~h}$ (without FK506 or 3-NP). Then, cells were washed briefly in phosphate buffer (PBS, in mM: $137 \mathrm{NaCl}$, $2.7 \mathrm{KCl}, 1.4 \mathrm{~K}_{2} \mathrm{HPO}_{4}, 4.3 \mathrm{Na}_{2} \mathrm{HPO} 4, \mathrm{pH} 7.4$ ), fixed in $4 \%$ paraformaldehyde ( $\mathrm{pH} 7.4$ ) for $10 \mathrm{~min}$ and incubated with $7.5 \mu \mathrm{g} /$ $\mathrm{ml}$ Hoechst dye for $10 \mathrm{~min}$. After washing twice in PBS, the coverslips were fixed to glass slide with mounting medium. Fluorescence of stained chromatin was examined and scored with a Nikon Diaphot TMD microscope (Nikon Corporation, Tokyo, Japan), using a triple XF-63 Omega filter (Omega Optical Inc., Brattleboro, VT, USA).

\section{Western blotting analysis}

The culture medium was removed, and cells were washed in ice-cold sucrose buffer, containing (in $\mathrm{mM}$ ): 250 sucrose, 20 HEPES/KOH (pH 7.4), 1 EGTA, and 1 EDTA. The cells were extracted in sucrose buffer supplemented with $1 \mathrm{mM}$ DTT, $1 \mathrm{mM}$ PMSF, and 1:1000 protease inhibitor cocktail, on ice. Lysates were homogenized and centrifuged $\left(4^{\circ} \mathrm{C}\right)$ at $500 \times g$ for $12 \mathrm{~min}$ to pellet the nucleus and cell debris. The supernatant (total fraction) was further centrifuged at $12,000 \times g$ for $20 \mathrm{~min}$. The resulting pellet (mitochondrial fraction) was resuspended in supplemented sucrose buffer. TCA $15 \%$ was added to the supernatant and centrifuged at $15,800 \times g$ for $10 \mathrm{~min}$. The resulting pellet (cytosolic fraction) was resuspended in supplemented sucrose buffer and brought to $\mathrm{pH} 7$ with $\mathrm{KOH}$. Protein content was determined by the method of Sedmak and Grossero (1977), and samples were frozen at $-80^{\circ} \mathrm{C}$. Equivalent amounts of protein were separated on a $6.5-15 \%$ SDS-PAGE gel and electroblotted onto polyvinylidene difluoride (PVDF) membranes (Amersham). After blocking with 5\% skim milk in TBS $(25 \mathrm{mM}$ Tris-HCl, $\mathrm{pH} 7.6,150 \mathrm{mM} \mathrm{NaCl} / 0.1 \%$ Tween, for $2 \mathrm{~h}$ (RT), the membranes were incubated with the antibodies directed against the denatured form of cytochrome $c$ (1:500), Bad (1:250), Bax (1:250), Bcl-2 (1:500), or $\alpha$-spectrin (1:2500), overnight at $4{ }^{\circ} \mathrm{C}$. The membranes were further incubated with the secondary mouse antibody $(1: 20,000)$, and the proteins were visualized by using an enhanced chemifluorescence reagent (Amersham Biosciences, Buckinghamshire, UK). The antibody directed against $\alpha$-tubulin $(1: 1000)$ was used to normalize the amount of protein per lane.

\section{Statistical analysis}

Data are expressed as mean \pm SEM of the number of experiments indicated in the figure legends. Comparisons among multiple groups were performed with a one-way analysis of variance (ANOVA) followed by a Tukey-Kramer post hoc test. Comparisons between two groups were achieved with Student $t$ test (GraphPad Prism Version 3.0). Significance was accepted at $P<0.05$. 


\section{Results}

FK506 prevents mitochondrial cytochrome $c$ release induced by $3-N P$

We first analyzed the changes in cell viability and intracellular $\mathrm{pH}$ after exposure of primary cultured cortical neurons to increasing concentrations of 3-NP, a neurotoxin known to irreversibly inhibit mitochondrial complex II (Coles et al., 1979). The reducing capacity of the cells, determined using the MTT assay, was dose-dependently decreased in the presence of 3$\mathrm{NP}$, as shown in Table 1 . Incubation of cultured neurons with 0.1 and $0.3 \mathrm{mM} 3-\mathrm{NP}$ decreased MTT reduction by about $7.7 \%$ and $16.5 \%$, respectively, whereas $1-10 \mathrm{mM}$ 3-NP decreased MTT reduction by $30-50 \%$, suggesting a massive loss of cell-reducing capacity. The integrity of the plasma membrane was also analyzed by following the LDH leakage. Exposure of cells to 0.1 and 0.3 $\mathrm{mM} 3$-NP did not significantly alter LDH leakage, compared to the control (untreated neurons) (Table 1). However, in the presence of 1-10 mM 3-NP, the release of LDH was significantly increased. These data show that the cell-reducing status is affected under 3-NP concentrations that do not alter the integrity of the plasma membrane. To determine if any changes in intracellular $\mathrm{pH}$ (pHi) could account for the loss of cell viability in the presence of 3-NP, we used the $\mathrm{pH}$-sensitive probe BCECF to verify the $\mathrm{pHi}$ upon incubation with increasing 3-NP concentrations (2 to 10 $\mathrm{mM})$. With the exception of a significant reduction in $\mathrm{pHi}$ in neurons exposed to $10 \mathrm{mM} 3-\mathrm{NP}$, no other changes were observed (Table 2). Furthermore, and as expected, extracellular $\mathrm{pH}(\mathrm{pHe})$, measured at the end of each experiment, was not significantly changed.

Data shown in Table 1 indicated that $0.1-0.3 \mathrm{mM}$ 3-NP was not associated with a massive necrotic cell death, as no significant changes in cell viability, determined by LDH leakage, were observed. Under these conditions, we analyzed the levels of mitochondrial and cytosolic cytochrome $c$ by Western blotting. Control cells exhibited almost undetectable levels of cytosolic cytochrome $c$ (Fig. 1). In contrast, there was a significant accumulation of cytochrome $c$ in the cytosol after incubation of cells with $0.3-3 \mathrm{mM}$ 3-NP (Fig. 1B), whereas mitochondrial
Table 2

Intracellular $\mathrm{pH}$ upon exposure to 3-nitropropionic acid

\begin{tabular}{lll}
\hline & $\mathrm{pHi}$ & $\mathrm{pHe}$ \\
\hline Control & $6.99 \pm 0.15$ & $7.31 \pm 0.013$ \\
3-NP & & \\
$2 \mathrm{mM}$ & $6.88 \pm 0.19$ & $7.31 \pm 0.024$ \\
$3 \mathrm{mM}$ & $7.01 \pm 0.43$ & $7.31 \pm 0.011$ \\
$6 \mathrm{mM}$ & $7.00 \pm 0.05$ & $7.34 \pm 0.012$ \\
$10 \mathrm{mM}$ & $6.29 \pm 0.15^{*}$ & $7.33 \pm 0.050$ \\
\hline
\end{tabular}

Intracellular $\mathrm{pH}(\mathrm{pHi})$ was measured after incubation with 2-10 mM 3-NP for $24 \mathrm{~h}$. pHi was determined in cortical neurons loaded with $5 \mu \mathrm{M}$ BCECF$\mathrm{AM}$ for $45 \mathrm{~min}$ at $37^{\circ} \mathrm{C}$. The neurons were further incubated for $20 \mathrm{~min}$ in the absence of the probe. Fluorescence (ratio $490 / 440 \mathrm{~nm}$ ) was measured in $\mathrm{Na}^{+}$medium at $\mathrm{pH}$ 7.4. Calibration of fluorescence was performed in $\mathrm{K}^{+}$ medium $(132 \mathrm{mM} \mathrm{KCl})$, in the presence of $10 \mu \mathrm{M}$ nigericin. Extracellular $\mathrm{pH}(\mathrm{pHe})$ was measured at the end of each experiment. Data, obtained after 10-min fluorescence measurement, are the means \pm SEM of 4-10 separate experiments, run in duplicates.

${ }^{*} P<0.05$ compared to the control.

cytochrome $c$ was reduced by about $30 \%(P<0.01)$ (Fig. 1A). Next, we evaluated whether FK506 $(1 \mu \mathrm{M})$, a selective inhibitor of calcineurin (Griffith et al., 1995; Liu et al., 1991), prevents mitochondrial cytochrome $c$ release induced by 3 -NP $(0.3 \mathrm{mM})$. We observed that FK506 prevented the release of cytochrome $c$, decreasing cytosolic levels to control values $(P<0.01)$ (Figs. $1 \mathrm{C}, \mathrm{D})$. Under these conditions, both cellular reduction capacity and the integrity of the plasma membrane were not significantly affected by exposure to FK506 in the presence of 3-NP (Table 1).

Given that FK506 is a selective inhibitor of calcineurin (Griffith et al., 1995; Liu et al., 1991), we also examined the changes in calcineurin activity induced by FK506 and 3-NP. We observed that, although FK506 $(1 \mu \mathrm{M})$ significantly decreased calcineurin activity (approximately $50 \%, P<0.05$ ), no change in calcineurin activity was observed upon exposure of cortical neurons to $0.3 \mathrm{mM} 3-\mathrm{NP}$ alone (Fig. 2). However, FK506 greatly reduced calcineurin activity in 3-NP-treated neurons (approximately $60 \%, P<0.05$, vs. 3-NP-treated neurons). Changes in calcineurin activity due to exposure to FK506, in the absence or in the presence of 3-NP, were not significantly different.

Table 1

Analysis of changes in cell viability induced by 3-nitropropionic acid

\begin{tabular}{lllll}
\hline & \multicolumn{2}{l}{ MTT reduction $(\%$ of control) } & & \multicolumn{2}{l}{ LDH leakage $(\%$ of total $)$} \\
\cline { 2 - 4 } & -FK506 & +FK506 $(1 \mu \mathrm{M})$ & $23.48 \pm 2.04$ & $+\mathrm{FK} 506(1 \mu \mathrm{M})$ \\
\hline Control & $100.0 \pm 0.19$ & $105.4 \pm 4.26$ & $26.65 \pm 3.97$ & $26.99 \pm 4.18$ \\
$3-\mathrm{NP}$ & & & $27.19 \pm 2.99$ & $26.63 \pm 2.80$ \\
$0.1 \mathrm{mM}$ & $92.32 \pm 1.22^{* *}$ & $94.18 \pm 5.33$ & $32.10 \pm 2.52^{*}$ & $31.46 \pm 5.23$ \\
$0.3 \mathrm{mM}$ & $83.46 \pm 2.61^{* *}$ & $88.03 \pm 1.80$ & $32.02 \pm 2.25^{*}$ & $26.97 \pm 3.89$ \\
$1 \mathrm{mM}$ & $70.19 \pm 1.93^{* * *}$ & $77.64 \pm 0.94^{\#}$ & $34.87 \pm 1.16$ \\
$3 \mathrm{mM}$ & $66.26 \pm 3.71^{* * *}$ & $70.10 \pm 1.73$ & $39.43 \pm 8.58^{*}$ & $34.63 \pm 9.66$ \\
$10 \mathrm{mM}$ & $52.02 \pm 1.05^{* * *}$ & $61.37 \pm 0.07^{*}$ & \\
\hline
\end{tabular}

Cortical neurons were pretreated with $1 \mu \mathrm{M}$ FK506 and incubated in the absence or in the presence of $0.1-10 \mathrm{mM} 3-\mathrm{NP}$ for $24 \mathrm{~h}$. The reduction capacity of the cells was analyzed by measuring the reduction of the tetrazolium salt MTT to formazan. These results were expressed as the \% of optical density observed in the control (untreated neurons). The integrity of the plasma membrane was determined by monitoring the leakage of LDH by following the rate of conversion of NADH to $\mathrm{NAD}^{+}$at $340 \mathrm{~nm}$. LDH released into the extracellular medium was expressed as a percentage of the total LDH activity in the cells. The results were expressed as the means \pm SEM of three to seven experiments, performed in duplicates.

${ }^{*} P<0.05$, compared to untreated neurons.

${ }^{* * *} P<0.01$, compared to untreated neurons.

*** $P<0.001$, compared to untreated neurons.

\# $P<0.05$, compared to 3-NP-treated neurons in the absence of FK506. 
A

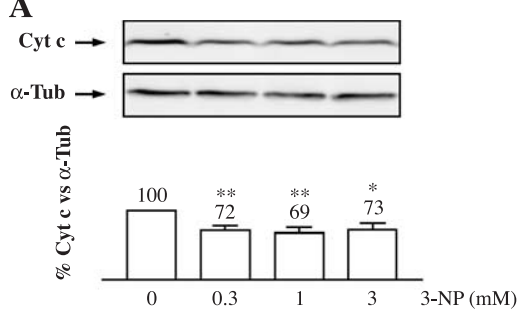

C

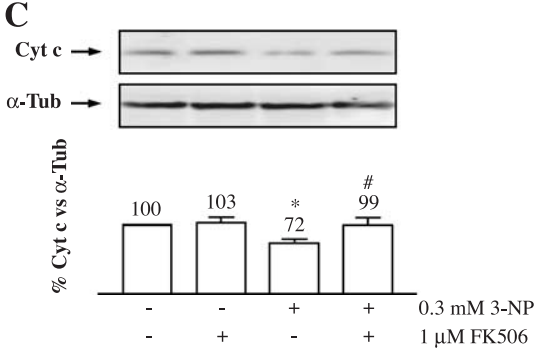

B

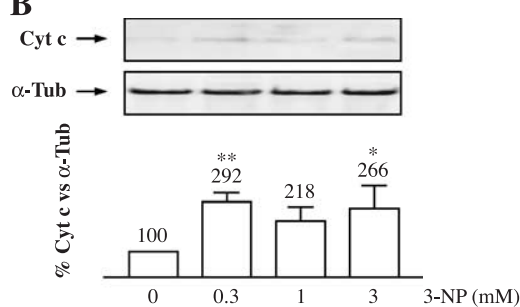

D

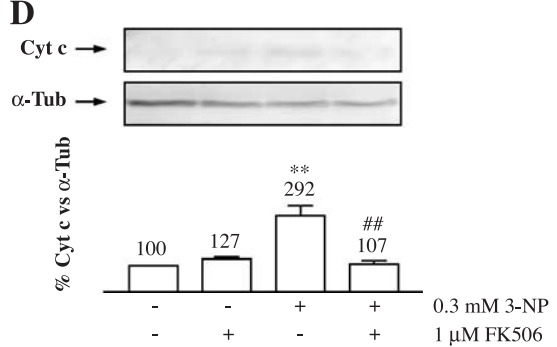

Fig. 1. FK506 prevents mitochondrial cytochrome $c$ release induced by 3-NP. (A, B) Cortical neurons were incubated in the absence or presence of $0.3-3 \mathrm{mM}$ 3-NP for $24 \mathrm{~h}$. (C, D) Cortical neurons were pretreated with $1 \mu \mathrm{M}$ FK506 for $20 \mathrm{~min}$ and then incubated in the absence or presence of $0.3 \mathrm{mM} 3-\mathrm{NP}$ for $24 \mathrm{~h}$. Cytochrome $c$ (Cyt c) content in cytosolic (B, D) and mitochondria-enriched fractions (A, C) was detected as a 15-kDa band by Western blot analysis. (Blots) Representative experiment from three to six different experiments producing the same results. (Graphs) Densitometric analysis of Cyt $\mathrm{c}$ upon normalizing Cyt $\mathrm{c}$ signal to the $\alpha$-tubulin band. Data were expressed as the mean \pm SEM of three to six different experiments. Statistical analysis: ${ }^{*} P<0.05, * * P<0.01$, compared to untreated neurons; ${ }^{\#} P<0.05,{ }^{\# \#} P<0.01$, compared to 3-NP-treated neurons in the absence of FK506.

FK506 prevents caspase-3 activation in cortical neurons exposed to $3-N P$

The release of cytochrome $c$ can precede and/or follow the activation of several caspases. Therefore, we next determined the activation of caspases $-2,-3,-8$, and -9 upon exposure of cells to increasing concentrations of 3 -NP. We further determined whether FK506 prevents 3-NP-induced caspases activities. As shown in Fig. 3 , all the caspases were dose-dependently activated by $3-\mathrm{NP}$. Caspases-2 and -9-like activities increased significantly in the presence of 1-3 mM 3-NP, but not in the presence of a lower concentration of 3-NP $(0.3 \mathrm{mM})$ (Figs. 3A, D). An increase in

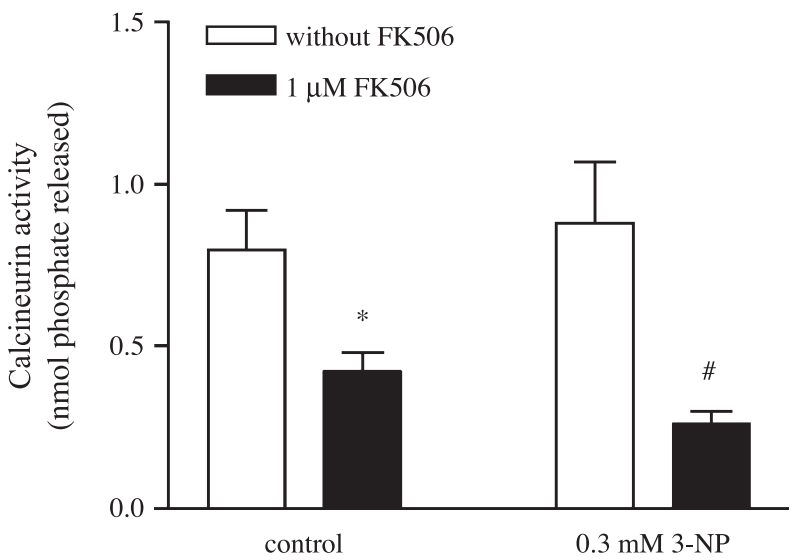

Fig. 2. Effect of 3-NP and FK506 on calcineurin activity. Cortical cultures were pretreated with $1 \mu \mathrm{M}$ FK506 and then incubated in the absence or in the presence of $0.3 \mathrm{mM} 3-\mathrm{NP}$ for $24 \mathrm{~h}$. Cell lysates prepared from collected neurons were assayed for calcineurin activity as described in Materials and methods. Data were expressed as the mean \pm SEM of three different experiments. Statistical analysis: $* P<0.05$, compared to untreated neurons; ${ }^{\#} P<0.05$, compared to 3-NP-treated neurons in the absence of FK506. caspase-8-like activity was observed in the presence of $3 \mathrm{mM} 3-\mathrm{NP}$ $(P<0.05)$ (Fig. 3C). In contrast, caspase-3-like activity was increased significantly in the presence of all concentrations tested (Fig. 3B). FK506 $(1 \mu \mathrm{M})$ completely prevented caspase-3-like activity induced by $3-\mathrm{NP}$ in the presence of $0.1(P<0.05)$ or $0.3 \mathrm{mM}$ 3 -NP $(P<0.01)$, but not in the presence of 1 or $3 \mathrm{mM} 3-\mathrm{NP}$ (Fig. 3B). Nevertheless, FK506 did not significantly prevent the increase in the activities of caspases-2, -8 , or -9 (Figs. 3A, C, D).

As reported previously (Bizat et al., 2003; Nasr et al., 2003), 3NP-induced cell death can involve the activation of both caspases and calpains. To examine the mechanism(s) underlying cortical neuronal degeneration induced by 3-NP, we studied the breakdown pattern of fodrin (nonerythroid $\alpha$-spectrin), a sensitive substrate of both calpains and caspase-3. The antibody used recognizes the carboxy terminus of $\alpha$-spectrin. Calpain-mediated cleavage of fodrin leads to 150 - and $145-\mathrm{kDa}$ doublet, whereas caspase-3mediated cleavage results in breakdown products of 150 and $120 \mathrm{kDa}$. As shown in Fig. 4A, a specific caspase-3-dependent cleavage of fodrin, leading to accumulation of the 150- and 120$\mathrm{kDa}$ products, was detected in the presence of $0.3-3 \mathrm{mM} 3-\mathrm{NP}$. Moreover, the intensity of the 150 - and $120-\mathrm{kDa}$ bands increased in a dose-dependent manner. These results are in agreement with that shown in Fig. 3B. A $145-\mathrm{kDa}$ breakdown product, indicative of calpain activity, was only slightly detected upon treatment with 3 mM 3-NP (Fig. 4A).

To assess the proteolytic activity of calpains, we measured the cleavage of Suc-LLVY-AMC, a fluorogenic substrate cleaved by calpains (Sasaki et al., 1984). However, no significant changes in calpain activity were observed in the presence of increasing concentrations of 3-NP (Fig. 4B).

\section{Effect of FK506 on nuclear fragmentation/condensation}

As a means to evaluate cells entering into apoptosis due to caspase-3 activation, we next analyzed the nuclear morphology of 
A

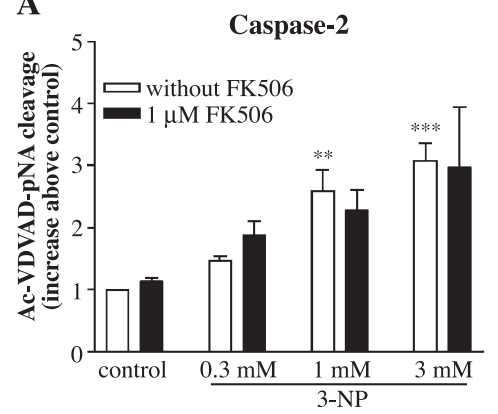

C

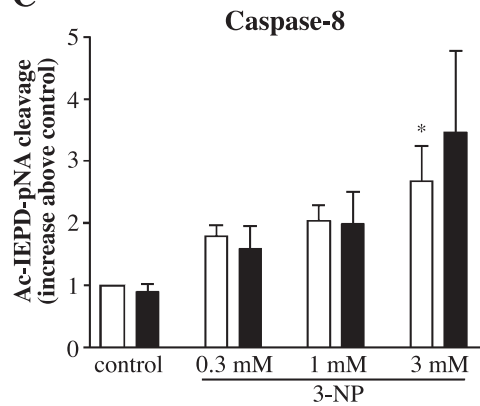

B

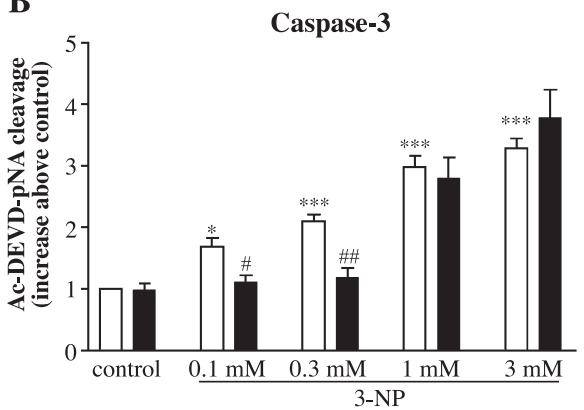

D

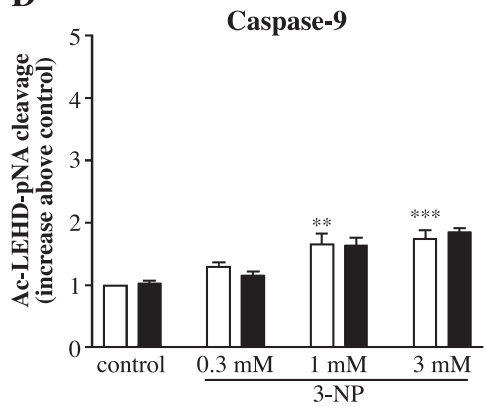

Fig. 3. Effect of FK506 on 3-NP-mediated activation of caspases-2, -3, -8, and-9. Cortical neurons were pretreated with $1 \mu \mathrm{M}$ FK506 and further incubated in the absence or presence of 0.1-3 mM 3-NP for 24 h. Caspase-2 (A), caspase-3 (B), caspase-8 (C), or caspase-9 (D)-like activities were measured by following the cleavage of the colorimetric substrates Ac-VDVAD- $p$ NA, Ac-DEVD- $p$ NA, Ac-IEPD- $p$ NA, or Ac-LEHD- $p$ NA, respectively. The activity was expressed as the increase of optical density values above the control (untreated neurons). The results were expressed as the mean \pm SEM of $3-10$ distinct experiments. Statistical analysis: ${ }^{*} P<0.05,{ }^{*} P<0.01,{ }^{* * *} P<0.001$, compared to the respective control; ${ }^{\#} P<0.05$, ${ }^{\# \#} P<0.01$, compared to 3 -NP-treated neurons in the absence of FK506.

cortical neurons exposed to 3-NP $(0.3-3 \mathrm{mM})$ for $24 \mathrm{~h}$, plus $24 \mathrm{~h}$ without stimuli. Control cells showed about $19.5 \% \pm 1.2 \%$ apoptotic cells, with condensed and/or fragmented chromatin (Fig. 5). In the presence of $0.3-3 \mathrm{mM} 3-\mathrm{NP}$, the number of neurons displaying condensed and/or fragmented chromatin increased in a dose-dependent manner: $0.3 \mathrm{mM}$ 3-NP decreased about $16.5 \% \pm 1.8 \%(P<0.01)$ the number of viable cells, relatively to the control (untreated neurons), whereas 1 and $3 \mathrm{mM}$ 3 -NP decreased about $25.0 \% \pm 4.2 \%(P<0.001)$ and $29.2 \% \pm$ $0.1 \%(P<0.001)$ the number of viable cells, respectively. Under these conditions, FK506 prevented 3-NP-induced apoptotic mor- phology in the presence of $0.3 \mathrm{mM} 3-\mathrm{NP}(P<0.05)$, but not in the presence of 1-3 mM 3-NP (Fig. 5). These data appear to be in accordance with FK506-mediated prevention of caspase-3 activity induced by 3-NP (Fig. 3B).

\section{FK506 decreases Bax and increases Bcl-2 in the mitochondria}

Our results suggested that FK506 modulates 3-NP-induced apoptosis by preventing cytochrome $c$ release and activation of the apoptotic cascade. Therefore, to further characterize the mechanism by which FK506 prevents 3-NP-induced apoptosis,
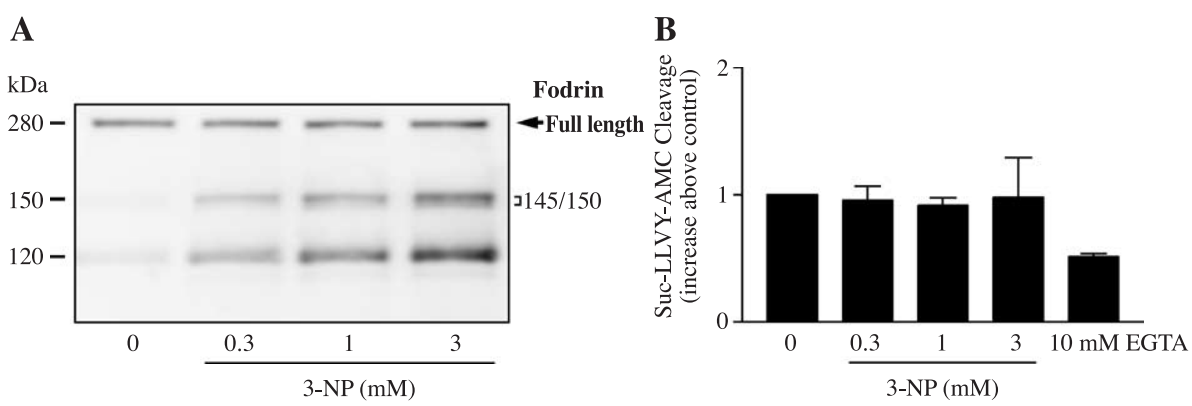

Fig. 4. Effect of 3-NP on calpain activity. Cortical neurons were incubated in the absence or presence of 0.3-3 mM 3-NP for 24 h. (A) Total fractions prepared from cortical neurons were analyzed by SDS-PAGE followed by Western blot for fodrin (known substrate of calpain and caspase-3). Calpain-mediated cleavage of fodrin leads to 150- and 145-kDa doublet, whereas caspase-3-mediated cleavage results in breakdown products of 150- and 120-kDa. (B) Calpaindependent proteolytic activity was measured by following the cleavage of the fluorogenic substrate Suc-LLVY-AMC. The activity was expressed as the increase of fluorescence arbitrary units values above the control (untreated neurons). The results were expressed as the mean \pm SEM of three distinct experiments performed in duplicates or triplicates. 


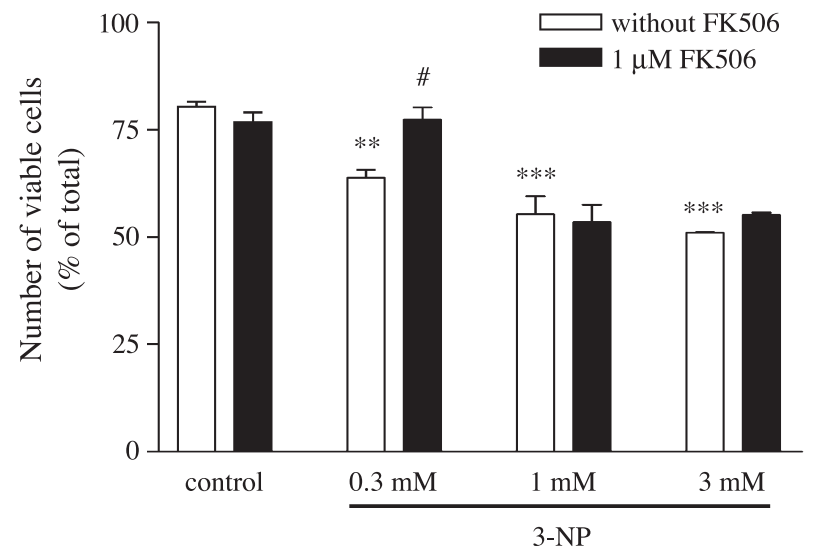

Fig. 5. Effect of FK506 on 3-NP-mediated apoptotic morphology. The cells were pretreated with $1 \mu \mathrm{M}$ FK506 and further exposed to 3-NP (0.3$3 \mathrm{mM}$ ) for $24 \mathrm{~h}$. After incubation, the medium was replaced by new neurobasal medium and the cortical neurons remained in culture for more $24 \mathrm{~h}$ (without FK506 or 3-NP). Fixed cells were labeled with Hoechst 33342 dye and assayed for nuclear morphology. Cell viability was expressed as a percentage of the total number of cells (approximately 100 cells per field were counted). Results were expressed as the mean \pm SEM of four distinct experiments, performed in duplicates. Statistical analysis: ${ }^{* *} P<0.01,{ }^{* * *} P<0.001$, compared to untreated neurons; ${ }^{\#} P<0.05$, compared to 3-NP-treated neurons in the absence of FK506.

we determined whether FK506 affects the redistribution of the Bcl-2 family proteins in the mitochondria. We analyzed the levels of Bad, Bax, and Bcl-2 by Western blot in whole cell lysates and in mitochondria-enriched fractions prepared from cortical cultures. As observed in Figs. 6A, C, E, $0.3 \mathrm{mM}$ 3-NP alone did not produce any significant alteration in mitochondrial levels of $\mathrm{Bad}$, $\mathrm{Bax}$, or Bcl-2. However, a significant decrease in mitochondrial Bax levels $(62.0 \% \pm 4.7 \%, P<0.001)$ (Fig. 6C) and a significant increase in mitochondrial Bcl-2 levels $(216.9 \% \pm$ 42.6\%, $P<0.01$ ) (Fig. 6E) were observed in the presence of FK506 and 3-NP. Interestingly, mitochondrial Bad levels were not significantly altered in the presence of 3-NP and FK506 (Fig. 6A). Under these conditions, Bad, Bax, and Bcl-2 levels on whole cell lysates remained unchanged (Figs. 6B, D, F), suggesting no major modifications in the expression of these proteins.

\section{Discussion}

In the present study, we showed that FK506 prevented mitochondrial-dependent apoptotic cell death induced by 3-NP. The calcineurin inhibitor highly prevented cytochrome $c$ release, caspase-3 activation, and apoptotic nuclei morphology. This protective effect was related to a decrease in mitochondrial Bax and an increase in mitochondrial Bcl-2. However, these alterations were not accompanied by changes of Bad levels in the mitochondria.

Several in vitro studies have established that 3-NP exposure induces both apoptosis and necrosis in striatal, cortical, and hippocampal cells (Behrens et al., 1995; Pang and Geddes, 1997). The balance between the two types of cell death depends mainly on the severity of ATP depletion (Eguchi et al., 1997; Leist et al., 1997; Ohgoh et al., 2000) which is closely related with the dose and time of exposure to this toxin. In general, low doses of 3-NP induce less damage and an apoptotic-like cell death, while higher doses result in acute injury and necrosis (Vis et al., 2002). Our results showed that low doses of $3-\mathrm{NP}(<1 \mathrm{mM})$ activate caspase3 and lead to DNA fragmentation, without affecting plasma membrane integrity, which is in agreement with the occurrence of an apoptotic process. In fact, 3-NP appears to activate the mitochondrial pathway in cortical neurons by inducing cytochrome $c$ release. Recently, Galas et al. (2004) showed that cytochrome $c$ was released into the cytoplasm in cortical cultures exposed to $0.1 \mathrm{mM} 3-\mathrm{NP}$, although this release was not associated with detectable caspase- 3 activation. In the presence of 1-3 mM 3-NP, caspases-2 and -8 were also activated, suggesting the involvement of the extrinsic pathway, which has been described to be dependent on the activation of death receptors (Schulze-Osthoff et al., 1998). Thus, depending on the concentration of 3-NP used, both apoptotic pathways could be responsible for the processing and activation of the effector caspase-3. Our results also suggested that, in the presence of higher 3-NP concentrations $(>1 \mathrm{mM})$, both apoptotic and necrotic cell death occurred. This could be confirmed by the observation that cytochrome $c$ release, caspase-3 activation, or DNA fragmentation were not further affected in the presence of 1$3 \mathrm{mM} 3-\mathrm{NP}$ and by the fact that LDH leakage was significantly increased. Furthermore, the analysis of the breakdown pattern of fodrin, a sensitive substrate of both calpains and caspase-3, showed a slight accumulation of the $145-\mathrm{kDa}$ calpain-mediated fodrin breakdown product only in the presence of $3 \mathrm{mM} 3-\mathrm{NP}$. These data suggest some activation of calpains, which are normally associated with necrotic processes (Nasr et al., 2003; Pang et al., 2003).

It has been shown that the elevation of intracellular calcium is an early and important event in 3-NP-induced neuronal death (Fukuda et al., 1998; Lee et al., 2002a). One of the consequences of calcium entering into the cell is the activation of several enzymes, namely, calcineurin. This calcium-dependent phosphatase has been described to be involved in many pathways that ultimately lead to cell death (Asai et al., 1999; Springer et al., 2000). Accordingly, inhibition of calcineurin as a relevant event in FK506-mediated protective effects has been demonstrated by many authors (Ankarcrona et al., 1996; Asai et al., 1999; Mobley and Agrawal, 2003; Nishino et al., 1996; Stevens et al., 2003). However, numerous other studies have excluded a substantial contribution of inhibited calcineurin for neuroprotection exerted by FK506 (Sabatini et al., 1997; Snyder et al., 1998; Toung et al., 1999; Yardin et al., 1998). According to our data, this phosphatase is only partially responsible for FK506-mediated neuroprotection upon mitochondrial inhibition, since its activity was not completely diminished in the presence of FK506. Furthermore, exposure to 3NP $(0.3 \mathrm{mM})$ did not affect calcineurin activity. Therefore, we cannot exclude a possible effect of FK506 independently of calcineurin inhibition. Interestingly, we observed that neither 3-NP (0.3 mM) nor FK506 was able to modify mitochondrial Bad levels, reinforcing the hypothesis that calcineurin inhibition may not determine the mechanism of neuroprotection induced by FK506. In accordance, Galas et al. (2004) were unable to detect changes in mitochondrial and cytosolic Bad upon exposure to $0.1 \mathrm{mM} 3-\mathrm{NP}$ in cortical cultures.

In our study, FK506 interfered only with components of the mitochondrial pathway. FK506 prevented the release of cytochrome $c$ from the mitochondria and caspase- 3 activation induced by low $(0.1-0.3 \mathrm{mM}) 3-\mathrm{NP}$ concentrations. This protective effect 

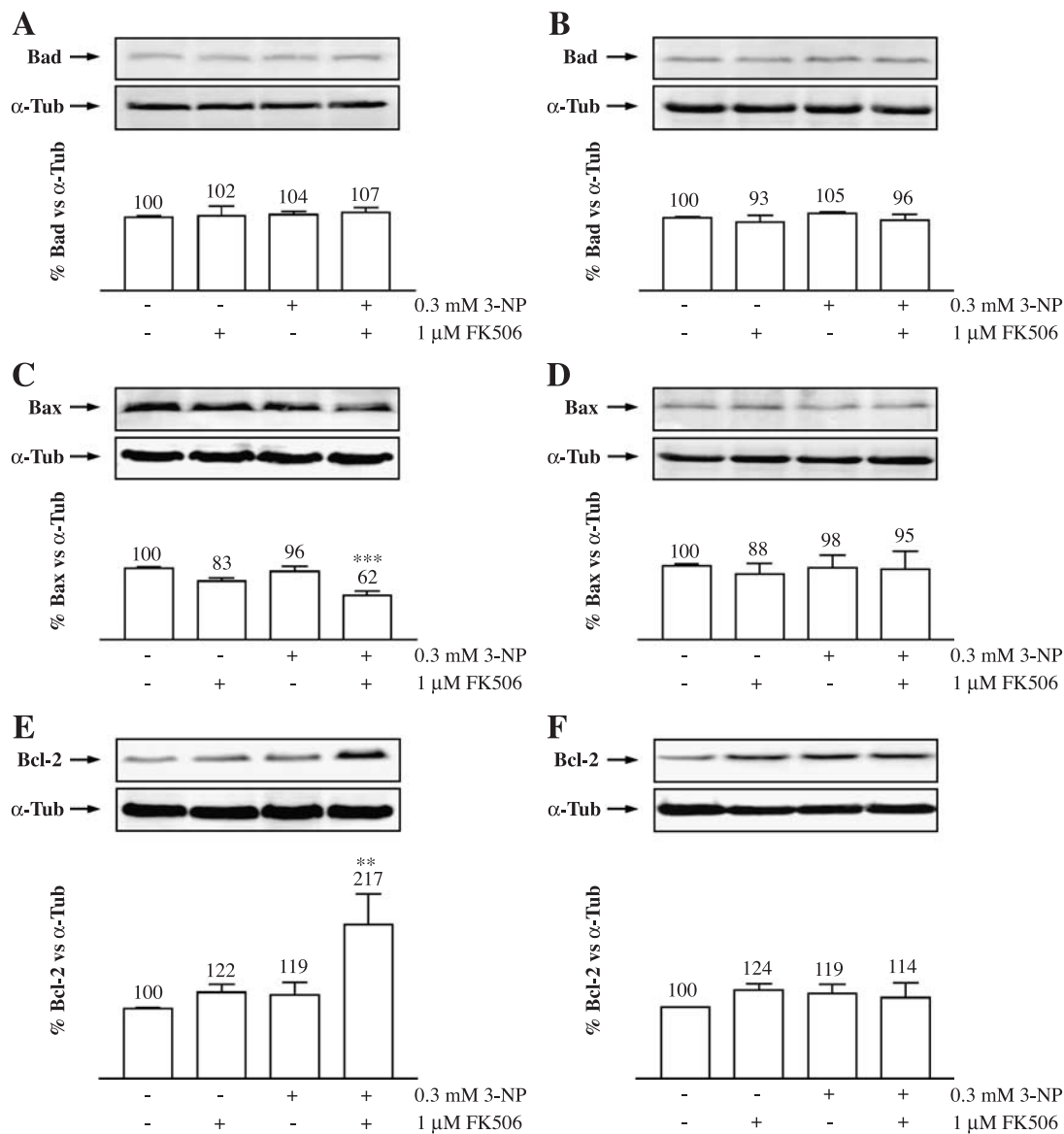

Fig. 6. FK506 decreases Bax levels and increases Bcl-2 levels in mitochondrial fractions. Cortical cultures were pretreated with $1 \mu \mathrm{M}$ FK506 and then incubated in the absence or in the presence of $0.3 \mathrm{mM} 3-\mathrm{NP}$ for $24 \mathrm{~h}$. Mitochondrial (A, C, E) and total (B, D, F) fractions prepared from cortical neurons were analyzed by SDS-PAGE followed by Western blot for Bad (A,B), Bax (C,D), and Bcl-2 (E,F). (Blots) Representative experiment from three to four different experiments producing the same results. (Graphs) Densitometric analysis performed by normalizing Bcl-2 family proteins signals to the $\alpha$-tubulin band. Data were expressed as the mean \pm SEM of three to four different experiments. Statistical analysis: $* * P<0.01, * * * P<0.001$, compared to 3-NP-treated neurons in the absence of FK506.

was also evident in the number of cells with apoptotic morphology. In the presence of higher concentrations of 3-NP (1-3 mM), FK506 was unable to prevent the activation of any caspases tested or the number of cells displaying nuclear fragmentation/condensation. FK506 also decreased Bax and increased Bcl-2 in the mitochondria of 3-NP-treated cells. It is well known that the Bcl-2 protein, which promotes cell survival, acts by disrupting the formation of Bax homodimers that promote cell death (Desagher and Martinou, 2000). Thus, the ratio of Bcl2 to Bax determines the survival or death of neurons following an apoptotic stimulus. Therefore, the alterations in the levels of these two proteins within the mitochondria could explain the protective effect of FK506 downstream this organelle. In accordance with this observation, we have previously demonstrated that overexpression of Bcl-2 effectively protects against 3-NP-induced toxicity (Brito et al., 2003).

Treatment with FK506 was previously shown to enhance phospho-cAMP response element binding protein (pCREB) immunoreactivity in hippocampal neurons and striatum slices (Merlio et al., 1993). pCREB is known to mediate the expression of a variety of genes, including brain-derived neurotrophic factor $(B D N F)$ (Beck et al., 1994), nerve growth factor (NGF) (Tao et al., 1998), c-fos (Walton et al., 1996), and bcl-2 (Wilson et al., 1996). Although, FK506 has been described to increase the transcription of the $b c l-2$ gene, it did not significantly affect total Bcl-2 levels in cortical neurons treated with 3-NP, suggesting no major modifications in the expression of this protein. Thus, the protective effect of FK506 appears to be mainly due to the alteration in the ratio of $\mathrm{Bcl}-2 / \mathrm{Bax}$ in the mitochondria.

In conclusion, this study clearly demonstrates the protective effect of FK506 in 3-NP-mediated apoptotic neuronal death and suggests that this molecule may be used in neuroprotective strategies against mitochondrial dysfunction occurring in Huntington disease.

\section{Acknowledgments}

We thank Dr. Paula Agostinho (Center for Neuroscience and Cell Biology of Coimbra) for introducing the technique of isolation of cortical neurons from rat embryos. We are also grateful to Dr. Caetana Carvalho and Inês Araújo (Center for Neuroscience and Cell Biology of Coimbra) for providing the anti- $\alpha$-spectrin antibody. This work was supported by "Fundação para a Ciência e a Tecnologia" (FCT), Portugal. 


\section{References}

Agostinho, P., Oliveira, C.R., 2003. Involvement of calcineurin in the neurotoxic effects induced by amyloid-beta and prion peptides. Eur. J. Neurosci. 17, 1189-1196.

Ankarcrona, M., Dypbukt, J.M., Orrenius, S., Nicotera, P., 1996. Calcineurin and mitochondrial function in glutamate-induced neuronal cell death. FEBS Lett. 394, 321-324.

Asai, A., Qiu, J.-H., Narita, Y., Chi, S., Saito, N., Shinoura, N., Hamada, H., Kuchino, Y., Kirino, T., 1999. High level calcineurin activity predisposes neuronal cells to apoptosis. J. Biol. Chem. 274, 34450-34458.

Beal, M.F., Brouillet, E., Jenkins, B.G., Ferrante, R.J., Kowall, N., Miller, J., Storey, E., Srivastava, R., Rosen, B., Hyman, B.T., 1993. Neurochemical and histologic characterization of striatal excitotoxic lesions produced by the mitochondrial toxin 3-nitropropionic acid. J. Neurosci. $13,4181-4192$.

Beck, T., Lindholm, D., Castren, E., Wree, A., 1994. Brain-derived neurotrophic factor protects against ischemic cell damage in rat hippocampus. J. Cereb. Blood Flow Metab. 14, 689-692.

Behrens, M.I., Koh, J., Canzoniero, L.M.T., Sensi, S.L., Csernansky, C.A., Choi, D.W., 1995. 3-Nitropropionic acid induces apoptosis in cultured striatal and cortical neurons. NeuroReport 6, 545-548.

Bergmeyer, H.U., Bernt, E., 1974. UV-assay with pyruvate and NADH. Methods of Enzymatic Analysis. Academic Press, New York, pp. 574-579.

Bizat, N., Hermel, J.M., Humbert, S., Jacquard, C., Creminon, C., Escartin, C., Saudou, F., Kajewski, S., Hantraye, P., Brouillet, E., 2003. In vivo calpain/caspase cross-talk during 3-nitropropionic acid-induced striatal degeneration. J. Biol. Chem. 278, 43245-43253.

Brito, O., Almeida, S., Oliveira, C.R., Rego, A.C., 2003. Bcl-2 prevents loss of cell viability and caspases activation induced by 3-nitropropionic acid in GT1-7 cells. Ann. N. Y. Acad. Sci. 1010, 148-152.

Brouillet, E., Guyot, M.C., Mittoux, V., Altairac, S., Condé, F., Palfi, S., Hantraye, P., 1998. Partial inhibition of brain succinate dehydrogenase by 3-nitropropionic acid is sufficient to initiate striatal degeneration in rat. J. Neurochem. 70, 794-804.

Browne, S.E., Bowling, A.C., Macgarvey, U., Baik, M., Berger, S.C., Muqit, M., Bird, E., Beal, M.F., 1997. Oxidative damage and metabolic dysfunction in Huntington's disease: selective vulnerability of the basal ganglia. Ann. Neurol. 41, 646-653.

Castilho, R.F., Hansson, O., Brundin, P., 2000. FK506 and cyclosporin A enhance the survival of cultured and graft embryonic dopamine neurons. Exp. Neurol. 164, 94-101.

Crabtree, G.R., 2001. Calcium, calcineurin, and the control of transcription. J. Biol. Chem. 276, 2313-2316.

Coles, C.J., Edmondson, D.E., Singer, T.P., 1979. Inactivation of succinate dehydrogenase by 3-nitropropionate. J. Biol. Chem. 254, 5161-5167.

Cregan, S.P., MacLaurin, J.G., Craig, C.G., Robertson, G.S., Nicholson, D.W., Park, D.S., Slack, R.S., 1999. Bax-dependent caspase-3 activation is a key determinant in p53-induced apoptosis in neurons. J. Neurosci. 19, 7860-7869.

Dawson, T.M., Steiner, J.P., Dinerman, J.L., Uhl, G.R., Snyder, S.H., 1993. Immunosuppressant, FK506, enhances phosphorylation of nitric oxide synthase and protects against glutamate neurotoxicity. Proc. Natl. Acad. Sci. U. S. A. $90,9808-9812$.

Desagher, S., Martinou, J.C., 2000. Mitochondria as the central control point of apoptosis. Trends Cell Biol. 10, 369-377.

Eguchi, Y., Shimizu, S., Tsujimoto, Y., 1997. Intracellular ATP levels determine cell death fate by apoptosis or necrosis. Cancer Res. 57, $1835-1840$

Fukuda, A., Deshpande, S.B., Shimano, Y., Nishino, H., 1998. Astrocytes are more vulnerable than neurons to cellular $\mathrm{Ca}^{2+}$ overload induced by a mitochondrial toxin, 3-nitropropionic acid. Neuroscience 87, 497-507.

Galas, M.-C., Bizat, N., Cuvelier, L., Bantubungi, K., Brouillet, E., Schiffmann, S.N., Blum, D., 2004. Death of cortical and striatal neurons induced by mitochondrial defect involves differential molecular mechanisms. Neurobiol. Dis. 15, 152-159.
Griffith, J.P., Kim, J.L., Kim, E.E., Sintchak, M.D., Thomson, J.A., Fitzgibbon, M.J., Fleming, M.A., Caron, P.R., Hsiao, K., Navia, M.A., 1995. X-ray structure of calcineurin inhibited by the immunophilinimmunosuppressant FKBP12-FK506 complex. Cell 82, 507-522.

Gu, M., Gash, M.T., Mann, V.M., Javoy-Agid, F., Cooper, J.M., Shapira, A.H., 1996. Mitochondrial defect in Huntington's disease caudate nucleus. Ann. Neurol. 39, 385-389.

Lee, W.T., Yin, H.S., Shen, Y.Z., 2002a. The mechanisms of neuronal death by mitochondrial toxin 3-nitropropionic acid: the roles of $N$-methyl-Daspartate glutamate receptors and mitochondrial calcium overload. Neuroscience 112, 707-716.

Lee, W.T., Itoh, T., Pleasure, D., 2002b. Acute and chronic alterations in calcium homeostasis in 3-nitropropionic acid-treated human NT2-N neurons. Neuroscience 113, 699-708.

Leist, M., Single, B., Castoldi, F., Kuhnle, S., Nicotera, P., 1997. Intracellular adenosine triphosphate (ATP) concentration: a switch in the decision between apoptosis and necrosis. J. Exp. Med. 185, 1481-1486.

Liu, J., Farmer, J.D., Lane, W.S., Friedman, J., Weissman, I., Schreiber, S.L., 1991. Calcineurin is a common target of cyclophilin-cyclosporin A and FKBP-FK506 complexes. Cell 66, 807-815.

Kim, G.W., Chan, P.H., 2001. Oxidative stress and neuronal DNA fragmentation mediate age-dependent vulnerability to the mitochondrial toxin, 3-nitropropionic acid, in the mouse striatum. Neurobiol. Dis. 8, $114-126$

Kramer, D., Fresu, L., Ashby, D.S., Freeman, T.C., Genazzani, A.A., 2003. Calcineurin controls the expression of numerous genes in cerebellar granule cells. Mol. Cell. Neurosci. 23, 325-330.

Merlio, J.P., Ernfors, P., Kokaia, Z., Middlemas, D.S., Bengzon, J., Kokaia, M., Smith, M.L., Siesjo, B.K., Hunter, T., Lindvall, O., 1993. Increased production of the TrkB protein tyrosine kinase receptor after brain insults. Neuron 10, 151-164.

Mobley, L.W., Agrawal, S.K., 2003. Role of calcineurin in calciummediated hypoxic injury to white matter. Spine J. 3, 11-18.

Mosmann, T., 1983. Rapid colorimetric assay for cellular growth and survival: application to proliferation and cytotoxicity assays. J. Immunol. Methods 65, 55-63.

Nasr, P., Gursahani, H.I., Pang, Z., Bondada, V., Lee, J., Hadley, R.W., Geddes, J.W., 2003. Influence of cytosolic and mitochondrial $\mathrm{Ca}^{2+}$, ATP, mitochondrial membrane potential, and calpain activity on the mechanism of neuron death induced by 3-nitropropionic acid. Neurochem. Int. 43, 89-99.

Nishino, H., Fujimoto, I., Shimano, Y., Hida, H., Kumazaki, M., Fukuda, A., 1996. 3-Nitropropionic acid produces striatum selective lesions accompanied by iNOS expression. J. Chem. Neuroanat. 10, 209-212.

Ohgoh, M., Shimizu, H., Ogura, H., Nishizawa, Y., 2000. Astroglial trophic support and neuronal cell death: influence of cellular energy level on type of cell death induced by mitochondrial toxin in cultured rat cortical neurons. J. Neurochem. 75, 925-933.

Pang, Z., Geddes, J.W., 1997. Mechanisms of cell death induced by mitochondrial toxin 3-nitropropionic acid: acute excitotoxic necrosis and delayed apoptosis. J. Neurosci. 17, 3064-3073.

Pang, Z., Bondada, V., Sengoku, T., Siman, R., Geddes, J.W., 2003. Calpain facilitates the neuron death induced by 3-nitropropionic acid and contributes to the necrotic morphology. J. Neuropathol. Exp. Neurol. $62,633-643$

Rego, A.C., Oliveira, C.R., 1998. Alteration of nitric oxide synthase activity upon oxidative stress in cultured retinal cells. J. Neurosci Res. $51,627-635$.

Rodrigues, C.M., Stieers, C.L., Keene, C.D., Ma, X., Kren, B.T., Low, W.C., Steer, C.J., 2000. Tauroursodeoxycholic acid partially prevents apoptosis induced by 3-nitropropionic acid: evidence for a mitochondrial pathway independent of the permeability transition. J. Neurochem. $75,2368-2379$.

Sabatini, D.M., Lai, M.M., Snyder, S.H., 1997. Neural roles of immunophilins and their ligands. Mol. Neurobiol. 15, 223-239.

Sasaki, T., Kikuchi, T., Yumoto, N., Yoshimura, N., Murachi, T., 1984. Comparative specificity and kinetic studies on porcine calpain I and 
calpain II with naturally occurring peptides and synthetic fluorogenic substrates. J. Biol. Chem. 259, 12489-12494.

Schulze-Osthoff, K., Ferrari, D., Los, M., Wesselborg, S., Peter, M.E., 1998. Apoptosis signaling by death receptors. Eur. J. Biochem. 254, $439-459$.

Sedmak, J.J., Grossero, S.E., 1977. A rapid, sensitive and versatile assay for protein using Coomassie brilliant blue G250. Ann. Biochem. 79, $544-552$.

Snyder, S.H., Lai, M.M., Burnett, P.E., 1998. Immunophilins in the nervous system. Neuron 21, 283-294.

Springer, J.E., Azbill, R.D., Nottingham, S.A., Kennedy, S.E., 2000. Calcineurin-mediated BAD dephosphorylation activates the caspase -3 apoptotic cascade in traumatic spinal cord injury. J. Neurosci. 20, 7246-7251.

Stevens, T.R., Krueger, S.R., Fitzsimonds, R.M., Picciotto, M.R., 2003. Neuroprotection by nicotine in mouse primary cortical cultures involves activation of calcineurin and L-type calcium channel inactivation. J. Neurosci. 23, 10093-10099.

Tao, X., Finkbeiner, S., Arnold, D.B., Shaywitz, A.J., Greenberg, M.E., 1998. $\mathrm{Ca}^{2+}$ influx regulates BDNF transcription by a CREB family transcription factor-dependent mechanism [published erratum appears in Neuron 20 (1998) 1297]. Neuron 20, 709-726.

Toung, T.J., Bhardwaj, A., Dawson, V.L., Dawson, T.M., Traystman, R.J., Hurn, P.D., 1999. Neuroprotective FK506 does not alter in vivo nitric oxide production during ischemia and early reperfusion in rats. Stroke $30,1279-1285$.

Vis, J.C., de Boer-van Huizen, R.T., Verbeek, M.M., de Waal, R.M., ten Donkelaar, H.J., Kremer, B., 2002. 3-Nitropropionic acid induces cell death and mitochondrial dysfunction in rat corticostriatal slice cultures. Neurosci. Lett. 329, 86-90.

Walton, M., Sirimanne, E., Williams, C., Gluckman, P., Dragunow, M., 1996. The role of the cyclic AMP-responsive element binding protein (CREB) in hypoxic-ischemic brain damage and repair. Mol. Brain Res. 43, $21-29$

Wang, H.G., Pathan, N., Ethell, I.M., Krajewski, S., Yamaguchi, Y., Shibasaki, F., McKeon, F., Bobo, T., Franke, T.F., Reed, J.C., 1999. $\mathrm{Ca}^{2+}$-induced apoptosis through calcineurin dephosphorylation of $\mathrm{Bad}$. Science 284, 339-343.

Wilson, B.E., Mochon, E., Boxer, L.M., 1996. Induction of bcl-2 expression by phosphorylated CREB proteins during Bcell activation and rescue from apoptosis. Mol. Cell. Biol. 16, 5546-5556

Wood, A.M., Bristow, D.R., 1998. N-methyl-D-aspartate receptor desensitisation is neuroprotective by inhibiting glutamate-induced apoptoticlike death. J. Neurochem. 70, 677-687.

Yardin, C., Terro, F., Lesort, M., Esclaire, F., Hugon, J., 1998. FK506 antagonizes apoptosis and c-jun protein expression in neuronal cultures. NeuroReport 9, 2077-2080. 